\title{
Alterations of Lipid Metabolism in Chronic Nephropathies: Mechanisms, Diagnosis and Treatment
}

\author{
Antonio Lacquaniti Davide Bolignano Valentina Donato Caterina Bono \\ Maria Rosaria Fazio Michele Buemi \\ Section of Nephrology, Department of Internal Medicine, University of Messina, Messina, Italy
}

\section{Key Words}

Lipid metabolism • Nephropathy · Cardiovascular disease •

Atherosclerosis $\cdot$ Dyslipidemia

\begin{abstract}
Nephropathic subjects show an increased tendency to develop cardiovascular diseases, mainly as the consequence of several risk factors including increased oxidative stress, inflammation, physical inactivity, anemia, vascular calcification, and endothelial dysfunction. The alterations in lipid metabolism represent a relatively lesser important cause of genesis and progression of atherosclerosis. Unfortunately, in these patients the atherogenic potential of dyslipidemia may depend more on apolipoproteins than on lipid abnormalities, and may not always be recognized by measurement of plasma lipids alone. The aim of this review was therefore to analyze the main lipid alterations that can occur in nephropathic patients, as well as their causes and their effects on the cardiovascular system. The clinical evidence and recommendations for the use of lipid-regulating drugs in patients with chronic kidney disease, nephrotic syndrome, in patients undergoing hemo- and peritoneal dialysis and in transplanted patients was also reviewed. Moreover, we analyzed the link between dyslipidemia and kidney disease onset and progression and the role of statins in preventing it.
\end{abstract}

Copyright $\odot 2010$ S. Karger AG, Basel

\section{Introduction}

Cardiovascular disease (CVD) represents the main cause of death in patients with end-stage renal disease. The risk for coronaropathy is higher in patients with renal impairment than in the general population and this evidence cannot be exclusively due to the 'traditional' risk factors.

The link between dyslipidemia and increased CVD risk in patients with chronic kidney disease (CKD) has been difficult to define, mainly due to the coexistence of several cardiovascular risk factors in patients with CKD, including increased oxidative stress, inflammation, physical inactivity, anemia, vascular calcification, endothelial dysfunction, and reduced nitric oxide availability.

The atherogenic potential of dyslipidemia in kidney disease may depend more on apolipoproteins than on lipid abnormalities, and may not always be recognized by measurement of plasma lipids alone [1,2].

This review focuses on dyslipidemias as they occur in patients with chronic nephropathy, describing their causes and their effects on the cardiovascular system. We also reviewed the clinical evidence and recommendations for the use of lipid-regulating drugs in patients with CKD, nephrotic syndrome (NS), those undergoing hemoand peritoneal dialysis, and in transplanted patients.

\section{KARGER}

Fax +41613061234 E-Mail karger@karger.ch www.karger.com

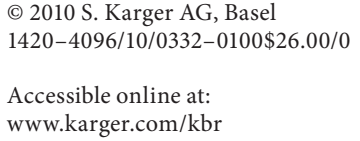

Prof. Michele Buemi

Via Salita Villa Contino, 30

IT-98100 Messina (Italy)

Tel. +39 090221 2265, Fax +39090 2935162

E-Mail buemim@unime.it 


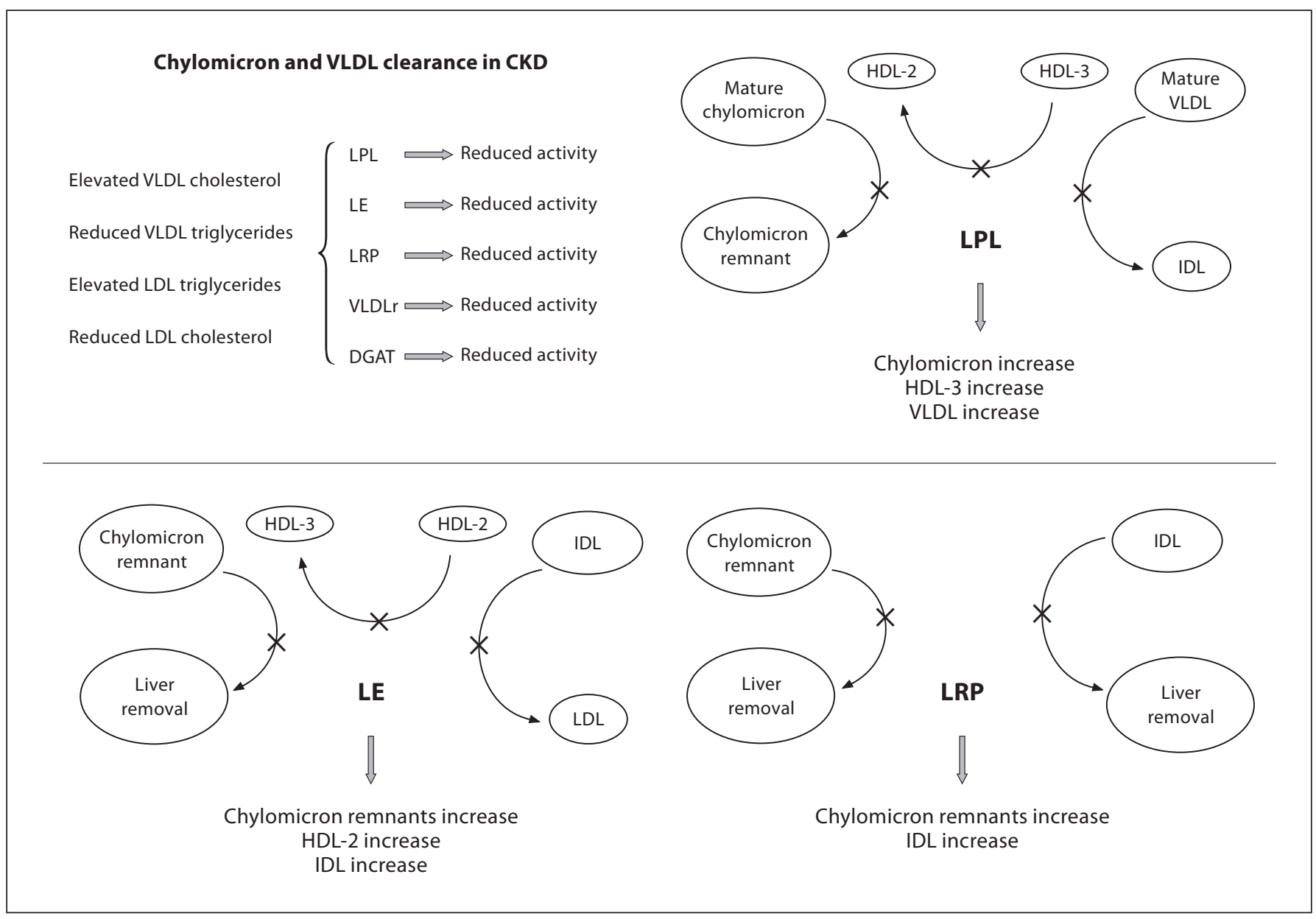

Fig. 1. Hypertriglyceridaemia in CKD patients: impaired clearance of chylomicrons and VLDL. The impaired clearance of the major lipoprotein involved in the metabolism of triglycerides, which characterizes chronic renal failure, is due to a reduced function of enzymes involved in their catabolism. CKD $=$ Chron- ic kidney disease; VLDL = very-low-density lipoprotein; LDL = low-density lipoprotein; LPL = lipoprotein lipase; $\mathrm{LE}=$ hepatic lipase; $L R P=L D L$ receptor protein; VLDLr $=$ VLDL receptor; DGAT $=$ acyl-CoA diaglycerol acyltransferase; HDL = high-density lipoprotein; IDL = intermediate density lipoprotein.
Moreover, we analyzed the link between dyslipidemia, kidney disease onset and progression, and the role of statins in preventing it.

\section{Chronic Kidney Disease}

CKD is associated with an early atherosclerotic process and with an increased cardiovascular morbidity and mortality [3].

Although the nature of dyslipidemia can be significantly influenced by several intrinsic (nephrotic proteinuria, concomitant diseases such as diabetes mellitus, hereditary disorders of lipid metabolism) or exogenous (erythropoietin, steroids, calcineurin inhibitors, etc.) factors, the most common quantitative lipid abnormalities in predialysis CKD patients are hypertriglyceridemia, reduced high-density lipoprotein (HDL) cholesterol levels as well as increased concentrations of lipoprotein(a) (Lp(a)) [4].

Total and LDL cholesterol levels are usually within normal limits or slightly reduced in these patients [5].

\section{VLDL and Triglyceride Levels}

Hypertriglyceridemia is partially due to a downregulation of lipoprotein lipase (LPL), hepatic lipase, verylow-density lipoprotein (VLDL) and low-density lipoprotein receptor (LDL-r) expression (fig. 1). 
Fig. 2. Impaired clearance of LDL and HDL in CKD. CKD = Chronic kidney disease; LDL = low-density lipoprotein; $\mathrm{HDL}=$ high-density lipoprotein; LCAT = lecithin-cholesterol acyltransferase; $\mathrm{CEPT}=$ cholesterol ester transfer protein; Apo = apolipoprotein; SRB-1 = scavenger receptor B1; ACAT = acyl-coenzyme A:cholesterol acyltransferase.

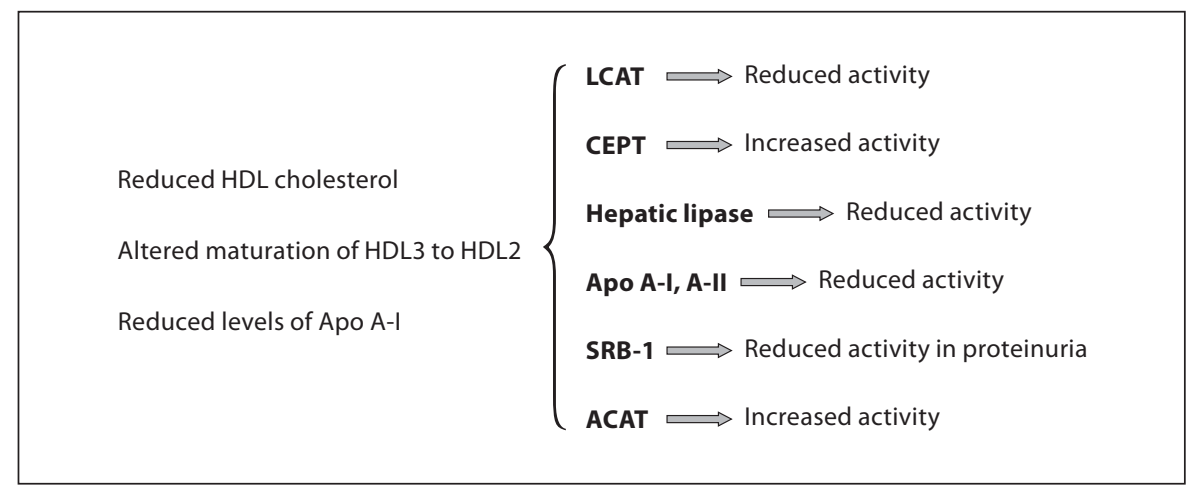

The increased plasma triglyceride levels can also be explained by significant increases in plasma levels of ApoC-III which is a potent inhibitor of LPL and is responsible for the degradation of triglyceride-rich particles.

Experimental studies revealed that the accumulation of triglyceride-rich lipoproteins such as VLDL, chylomicrons and their remnants in individuals with CKD is mainly due to their decreased catabolism [6].

In fact the downregulation of several genes, along with the changes in the composition of lipoprotein particles and the direct inhibitory effect of various uremic 'toxins' on the enzymes involved in lipid metabolism, represents the most important pathophysiological mechanisms underlying the development of hypertriglyceridemia in renal failure [7].

\section{High-Density Lipoprotein}

Reductions in plasma concentrations of apolipoprotein (ApoA) I and II, which are mandatory components of the HDL particle, are thought to play a large role in determining the low-HDL cholesterol levels. Patients with CKD have been shown to have reduced genetic expression of these apoproteins in the sites of HDL production in the liver [8].

Another factor contributing to low HDL levels is the profound inflammatory state of these patients. Chronic inflammation results in decreased albumin levels. Albumin is a carrier of free cholesterol from the peripheral tissues to HDL, and a reduction in albumin may contribute to reduce HDL levels [4].

The diminished activity of lecithin-cholesterol acyltransferase (which is the enzyme responsible for the esterification of free cholesterol in HDL particles) as well as increased activity of cholesteryl ester transfer protein (which facilitates the transfer of cholesterol esters from
HDL to triglyceride-rich lipoproteins) reduce the HDL cholesterol serum concentration [9, 10] (fig. 2).

\section{Low-Density Lipoprotein}

Although uremic patients usually have a normal or slightly reduced LDL cholesterol concentration, they exhibit important disturbances in the density distribution of LDL subfractions that are characterized by a predominance of small, dense LDL particles. These particles are more atherogenic than the large ones and can substantially contribute to the pathogenesis of atherosclerotic vascular disease [11].

\section{Lipoprotein(a)}

$\mathrm{Lp}(\mathrm{a})$ is similar in structure to LDL but is characterized by the presence of an additional protein called apolipoprotein(a), which is linked by a single disulfide bond to ApoB.

Numerous studies in the general population have demonstrated that $\mathrm{Lp}(\mathrm{a})$ represents a risk factor for CVD [12].

In kidney disease, plasma Lp(a) levels are significantly influenced by the glomerular filtration rate (GFR). In patients with large apo(a) isoforms, but not in those with small apo(a) isoforms, plasma $\mathrm{Lp}$ (a) levels begin to increase already in the earliest stages of renal impairment before GFR starts to decrease [13].

Then Lp(a) levels are elevated in CKD secondary to loss of functional renal tissue.

\section{Therapeutic Measures}

If therapeutic lifestyle changes (TLCs) are not sufficient to reduce triglycerides to $<500 \mathrm{mg} / \mathrm{dl}$, then treatment with a fibrate or nicotinic acid should be considered [14].

Studies from the general population suggest that fibrates and nicotinic acid lower triglycerides by $20-50 \%$ [15]. 
Fig. 3. Main pathogenetic mechanisms responsible of hyperlipidemia in nephrotic syndrome. The ability of the liver to capture circulating LDL is reduced because of low expression of the LDL receptor, due to its loss in the urine. This implies a low concentration of intrahepatic free cholesterol that determines the activation of compensatory pathways. An increased activity of HMG-CoA reductase and ACAT leads to an increased endogenous synthesis of cholesterol, while a reduced activity of the enzyme $7 \alpha$-hydroxylase results in lower use of cholesterol in the bile synthesis. The final result is an increased hepatic production of cholesterol that is poured into the circulation causing hypercholesterolemia. HMG-CoA reductase = 3-Hydroxy-3methylglutaryl CoA reductase; ACAT = acyl-coenzyme A:cholesterol acyltransferase; $\mathrm{LDL}=$ low-density lipoprotein.

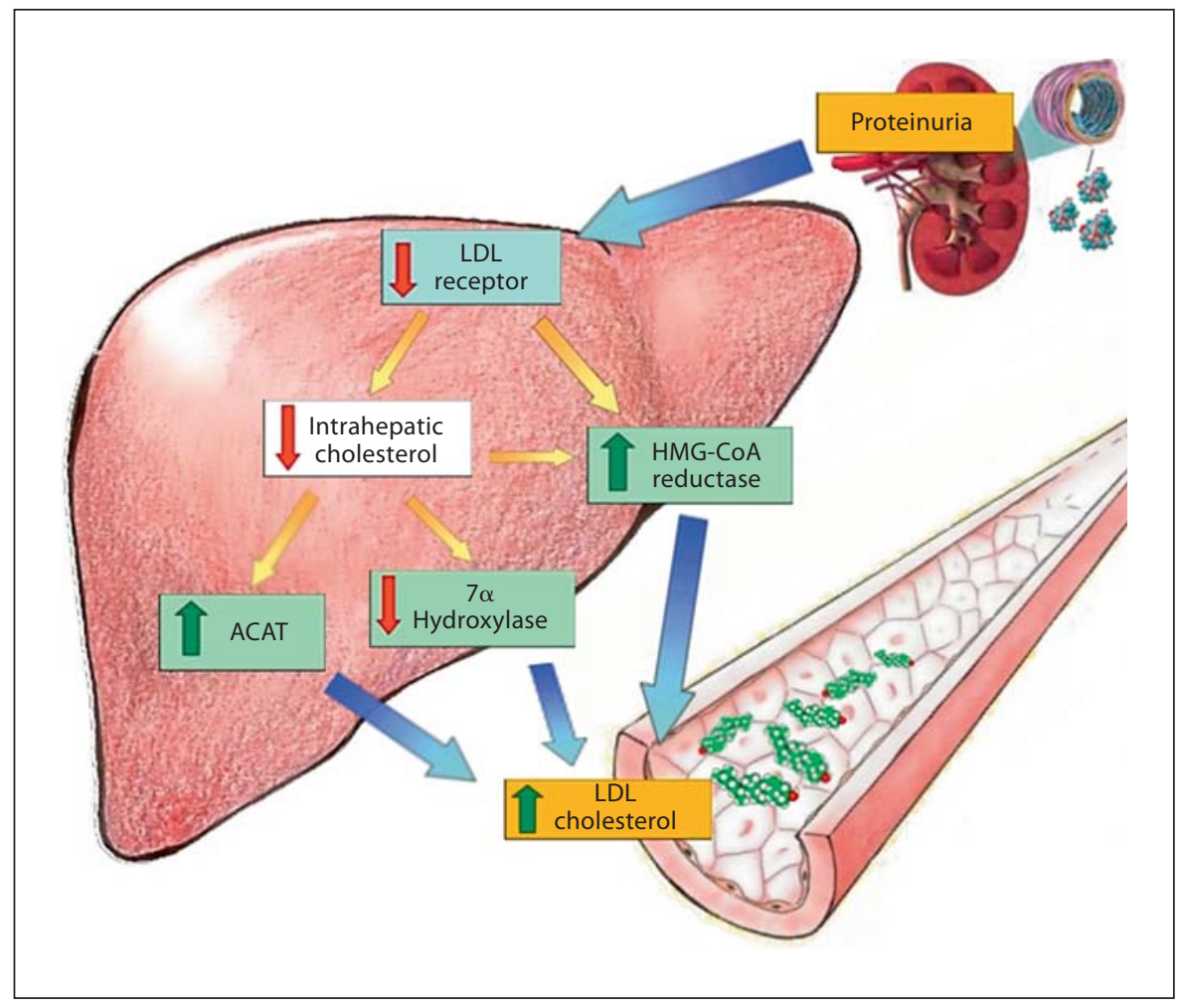

In any case, the benefits of drug therapy for hypertriglyceridemia should be weighed against the risks, and the risk of complications (particularly myositis and rhabdomyolysis) is increased in CKD.

In the VA-HIT study [16] that analyzed patients with established coronary heart disease, gemfibrozil increased HDL cholesterol levels by $5 \%$ and lowered triglyceride levels by $20 \%$ with no change in LDL cholesterol levels, and there was a $32 \%$ risk reduction in cardiac events.

The reduction in LDL that can be achieved with TLCs is generally modest. Therefore, TLCs alone are usually insufficient to reduce the LDL to the goal of $<100 \mathrm{mg} / \mathrm{dl}$. In patients who cannot reduce LDL to $<100 \mathrm{mg} / \mathrm{dl}$ by diet, a statin should be added, provided that there is no evidence of acute or chronic liver disease. Diet should be continued as an adjunct to the statin [14].

\section{Nephrotic Syndrome}

The most common lipid abnormalities in patients with NS are elevated concentrations of total and LDL cholesterol as well as a predominance of cholesterol-depleted small, dense LDL particles [17].
This pattern of abnormalities is due to several pathogenetic mechanisms. First, urinary protein loss stimulates an increased LDL synthesis. It is likely that proteinuria with the resultant hypoalbuminemia leads to an upregulation of 3-hydroxy-3-methylglutaryl CoA reductase [18].

This is due to a reduction in intra-hepatic free cholesterol because of a lower expression of the LDL-r. In fact recently published studies indicate that patients with NS exhibit an acquired LDL-r deficiency [19].

Moreover, these alterations lead to an increased intrahepatic activity of acyl-CoA cholesterol acyltransferase (ACAT), of the above-mentioned 3-hydroxy-3-methylglutaryl CoA reductase and to a downregulation of cholesterol $7 \alpha$-hydroxylase (an enzyme that catalyzes the limiting reaction of cholesterol catabolism which starts bile acid biosynthesis). Finally, this intrahepatic compensative mechanism determines the increased circulating LDL level typical of NS (fig. 3).

Conversely, low HDL with a poor maturation of HDL3 to cholesterol-rich HDL-2 is due to acquired lecithincholesterol acyltransferase deficiency secondary to abnormal urinary losses of this enzyme [20]. 
Impaired clearance of chylomicrons and VLDL has emerged as the dominant factor for the increased serum triglyceride concentration. Furthermore, the status of hypertriglyceridemia arises from increased hepatic VLDL synthesis driven by upregulation of hepatic acyl-CoA diaglycerol acyltransferase [21].

The development of this form of secondary dyslipidemia appears to be independent of the underlying renal disease and may substantially contribute to the increased cardiovascular risk that has been observed in these individuals as well as to the progression of renal failure [22].

Among the renal populations, proteinuric patients are at particularly high risk, as apparent from the observation of an almost 6-fold increased incidence of myocardial infarction in such patients [23].

Proteinuria-associated lipid abnormalities play a main role in the high cardiovascular risk in proteinuric patients, and thus provide an important treatment target based on statins administration.

In opposition, despite the above lipoprotein changes, Lechner et al. [24] have not shown a consistent relationship between NS, in the absence of uremia, and an increased risk of CVD.

\section{Therapeutic Measures}

In patients with proteinuria, a mild protective effect by statin treatment is suggested by the meta-analysis of Fried et al. [25] who reported on 13 randomized trials with small numbers of patients who were treated for short periods of time.

A study conducted on 43 patients with idiopathic NS has shown that the addition of fluvastatin $(20 \mathrm{mg} /$ day $)$ to the basic therapy significantly reduced cholesterolemia (about $40 \%$ ), proteinuria (60\%) and increased serum levels of albumin (60\%) [26].

Results similar to those of Gheith et al. [26] were obtained by Valdivesio et al. [27] after administration of atorvastatin $(10 \mathrm{mg} /$ day $)$ in 10 dyslipidemic patients with hypoalbuminemia and proteinuria $>3.5 \mathrm{~g} / 24 \mathrm{~h}$.

Rayner et al. [28] showed that, in patients with NS, alone the use of a diet low in lipids led to a minimal reduction in plasma cholesterol levels associated with little change in the urinary excretion of protein and normalization of serum albumin levels in the absence of treatment pharmacology.

Experience to date suggests that statins offer the most effective therapy and are relatively safe, at least in shortterm studies. The benefits of treatment remain unproven but may include a reduction in cardiovascular risk and preservation of residual renal function.

\section{Lipids and Progression of CKD}

Numerous animal studies have demonstrated that lipoprotein abnormalities appear to cause primary renal injury and can contribute to the progression of established renal disease regardless of etiology [29].

Hyperlipidemia can potentially accelerate progression of renal disease by several mechanisms. Reabsorption of fatty acids, phospholipids, and cholesterol contained in the filtered proteins (albumin and lipoproteins) by tubular epithelial cells can stimulate tubulointerstitial inflammation, foam cell formation, and tissue injury [30].

The accumulation of lipoproteins in glomerular mesangium can promote matrix production and glomerulosclerosis with the native and oxidized lipoproteins, particularly LDL, which stimulate production of matrix proteins by cultured mesangial cells and promote generation of proinflammatory cytokines, which can lead to recruitment and activation of circulating and resident macrophages [31].

A secondary analysis of the Modification of Diet in Renal Disease (MDRD) study demonstrated that low HDL cholesterol and triglyceride-rich lipoproteins were correlated with an unfavorable effect on the progression of renal disease [32]. Although experimental studies tend to support the hypothesis of detrimental impact of dyslipidemia on the progression of CKD, results of clinical studies, however, have been inconsistent as they have shown detrimental effects of high concentrations of triglycerides or low levels of HDL cholesterol [32], triglyceride-rich lipoproteins [33], apoB [34], and total cholesterol [35].

The existence of a link between dyslipidemia and oxidative stress in the pathogenesis of renal damage was shown in uninephrectomized rats, in which hyperlipidemia increased glomerular and tubulointerstitial infiltration and aggravated glomerulosclerosis [36].

Statins are highly effective in inhibiting progression of renal damage in numerous experimental models, mainly through their pleiotropic effects. Possible pathways for the protective action of statins, other than any hypocholesterolemic effect, are cellular apoptosis/proliferation balance, inflammatory cytokine production, and signal transduction regulation $[37,38]$.

Apoptosis also plays an important role in the kidney, preventing glomerular hypercellularity and scarring following experimental mesangial proliferating nephritis, and it has been suggested that it is a critical mechanism governing glomerular remodeling and the return to normal cellularity after inflammatory injury [39]. 
In an experimental model, Buemi et al. [40] observed a significant increase in apoptosis in cultures of human myocytes containing sera from fluvastatin-treated patients. Thus, a statin-dependent increase in apoptosis may explain the beneficial effect of these drugs in some forms of human glomerulonephritis [41]. In vivo studies suggested a variety of mechanisms whereby statins may have an impact on renal endothelial function $[42,43]$.

The proposed renal-protective mechanism is based on in vitro observations that statins impede the normal reabsorption of albumin in the proximal tubule. Mevalonate, a metabolite in the cholesterol synthetic pathway, is reduced in patients on statins and it is necessary for the normal reabsorption of albumin in the proximal renal tubule [44].

In summary, although statins may increase tubular proteinuria initially, they may reduce inflammation, slow fibrosis, and result in less proteinuria in the long-term [45]. In contrast, meta-analyses of participants with CVD in randomized controlled studies with statins, who had impaired renal function and/or proteinuria, show a modest though statistically significant reduction in the loss of eGFR with statins (except in patients with diabetic nephropathy or glomerulonephritis) as well as a modest significant reduction in proteinuria or albuminuria. However, the data on a reduction in proteinuria are currently not sufficient or compelling enough to justify recommendations to use statins with the rationale of attenuating the rate of loss of renal function [46].

\section{Hemodialysis}

Several observational studies have documented a 'strange' association between lower total cholesterol and mortality which was higher in patients with end-stage renal disease. This phenomenon represents a seemingly paradoxical reversal of the well-established association of higher lipid levels with mortality in the general population [47].

The well-known association of high cholesterol levels with increased mortality in the general population was not observed in dialysis patients without malnutrition or inflammation. If patients suffered from these conditions, a high cholesterol concentration was associated with a better outcome which might be explained by the cholesterol-lowering effect of systemic inflammation and malnutrition [48].

A similar interaction was described by Iseki et al. [49], who showed higher mortality with higher total choles- terol only in dialysis patients with serum albumin levels of $>4.5 \mathrm{~g} / \mathrm{dl}$. Besides this interaction with malnutrition/ inflammation, many other factors might contribute to the reverse epidemiologic findings in dialysis patients [50].

In patients who are on hemodialysis (HD), LDL cholesterol levels are generally normal, but triglyceride levels are high and HDL cholesterol levels are low. However, the Kidney Disease Outcomes Quality Initiative (K/DOQI) guideline review on dyslipidemias in patients with CKD found that $55.7 \%$ of patients who are on HD had LDL cholesterol levels of $>100 \mathrm{mg} / \mathrm{dl}$ [51].

The lipid and apolipoprotein profile that characterizes predialytic renal failure remains essentially unchanged during long-term $\mathrm{HD}$, with qualitative and quantitative alterations [52]. Several mechanisms might contribute to the impaired metabolism of LDL and IDL in uremic patients. However, the dialysis technique may result in additional defects in lipid homeostasis (such as increased catabolic rate of Apo A-I) that reinforce the clinical expression of these mechanisms [53].

It has been shown, for example, that the use of highflux polysulfone or cellulose triacetate membranes instead of low-flux membranes is accompanied by a significant reduction in serum triglyceride levels as well as by an increase in Apo A-I and HDL cholesterol levels [54].

Another factor that can potentially affect lipoprotein metabolism in HD patients is the repeated use of heparin as an anticoagulant. Heparin releases LPL from the endothelial surface and thus its chronic use may result in LPL depletion and defective catabolism of triglyceriderich lipoproteins. Näsström et al. [55] have demonstrated that the LPL activity rose rapidly when dalteparin was administered during dialysis treatment interfering with the LPL system and involving a depletion in LPL stores.

\section{Therapeutic Measures}

The work group for K/DOQI published the Clinical Practice Guidelines for Managing Dyslipidemias in CKD and proposed the adoption of Adult Treatment Panel III LDL-cholesterol targets for individuals with stage $5 \mathrm{CKD}$ $[15,56]$.

A Cochrane review, published in 2004, concluded that statins decreased serum cholesterol in dialysis patients as effectively as in the general population, but no conclusions were made about the effects of statins on cardiovascular mortality [57].

For patients on HD with elevated LDL, choosing statins with limited renal excretion, such as atorvastatin or fluvastatin, may be more important. Atorvastatin and 
its metabolites are excreted mostly in bile, and urinary excretion is low, so dosages do not have to be modified as GFR levels fall. Fluvastatin is almost completely metabolized by the liver with $<5 \%$ excreted in the urine. Simvastatin is almost completely metabolized by the liver [58]. $90 \%$ of rosuvastatin is excreted unchanged in the feces and only $10 \%$ in urine [59]. Ezetimibe is being used with increasing frequency in many patients to augment the LDL cholesterol-lowering effects of statins and no dosage adjustment of ezetimibe is needed in patients with renal insufficiency [60]. In mixed dyslipidemia, $\omega-3$ fatty acids may play a more prominent role because the National Lipid Association recommends avoiding fibrate use in patients with a GFR of $<15 \mathrm{ml} / \mathrm{min} / 1.73 \mathrm{~m}^{2}$ [61].

Several trials have been conducted, and some are in progress, to define the role of statins in the therapy of patients undergoing HD. The 4D Study (Die Deutsche Diabetes Dialyse Studie) demonstrated that there were no differences between the treated and untreated groups in the primary composite endpoint of cardiac death, stroke, or nonfatal myocardial infarction, and not at all in the atorvastatin group; there was a twofold increase in fatal strokes [62].

There are different explanations for the negative results of the 4D study: many cardiovascular events in dialysis patients were due to arrhythmia or non-ischemic cardiomyopathy, which might not be related to atherosclerosis, and also the atherosclerosis was so advanced that these patients were beyond obtaining benefit from drug therapy.

It is likely that in patients on dialysis the progression mechanisms of coronary heart disease differ from those operating in the general population. Fathi et al. [63] studied the effect of aggressive lowering of LDL cholesterol with atorvastatin comparing patients with primary coronary artery disease without renal dysfunction against patients with advanced renal failure. In non-renal patients the maximum intima/media thickness of the carotid artery decreased significantly by this intervention while it remained unchanged in patients with CKD [63].

Anatomical studies point in the same direction. Schwarz et al. [64] compared the coronary arteries of patients with coronary heart disease who either had no kidney disease or advanced CKD, and stressed that the coronary arteries of CKD patients had a dramatically 5 -fold higher prevalence of coronary calcification.

Similar conclusions to those obtained by the $4 \mathrm{D}$ trial emerged from the AURORA trial which was a randomized placebo-controlled trial with 2,700 HD patients using rosuvastatin $10 \mathrm{mg} /$ day [65].
The Study of Heart and Renal Protection (SHARP) is a large trial using statins in HD patients [66]. The 3,000 $\mathrm{HD}$ patients are randomized to simvastatin $20 \mathrm{mg} /$ day or simvastatin $20 \mathrm{mg} /$ day plus ezetimibe [66].

\section{Peritoneal Dialysis}

Patients who are on peritoneal dialysis (PD) tend to have higher LDL cholesterol levels and the K/DOQI guideline review found that $73.2 \%$ of patients had LDL cholesterol levels of $>100 \mathrm{mg} / \mathrm{dl}$.

Hypertriglyceridemia is the primary lipid abnormality in PD patients [67]. Coexistent insulin resistance and glucose loading from the peritoneal dialysate increase free fatty acid availability and de novo lipogenesis, key triggers to VLDL secretion, and the increased clearance of apolipoproteins across the peritoneal membrane during PD can also trigger profound dyslipidemia [68].

Babazono et al. [69] have underlined how a reduction in glucose load with the use of less absorbed icodextrincontaining dialysis solution instead of glucose for the overnight dwell sufficiently reduces the serum levels of total and LDL cholesterol as well as the concentrations of triglycerides and small dense LDL particles.

There are also mildly elevated LDL cholesterol levels with a marked predominance of highly atherogenic small dense LDL particles in these patients. Furthermore, HDL cholesterol levels are low [57].

PD patients have a more atherogenic lipid profile than HD subjects; they have lower HDL cholesterol, increased $\mathrm{LDL} / \mathrm{HDL}$ ratio, and higher Lp(a) levels due to the large amounts of protein losses in the dialysate fluid.

Despite this, the cardiovascular mortality rates do not differ between HD and PD patients; the reason for this is the fact that PD individuals have fewer hypotensive episodes and much fewer arrhythmias compared with HD individuals [70].

\section{Therapeutic Measures}

Statins also exert several other non-lipid properties that may contribute to cardiac risk reduction in $\mathrm{PD}$ patients. These include the improvement in endothelial function, the inhibition of smooth muscle cell proliferation, and the reduction in neointima formation, as well as the reduction in platelet reactivity and aggregation [71].

Another beneficial action of statins on PD patients includes the stimulation of peritoneal fibrinolytic activity to prevent peritoneal fibrin deposition and adhesion development in these patients [72]. 
Table 1. Alterations of both lipids and lipoprotein metabolism and respective therapies

\begin{tabular}{|c|c|c|c|c|c|}
\hline Nephropathies & Lipids & \multicolumn{2}{|c|}{ Lipoproteins } & \multicolumn{2}{|c|}{ Therapeutic measures } \\
\hline $\begin{array}{l}\text { Chronic kidney } \\
\text { disease }\end{array}$ & $\begin{array}{l}\text { Hypertriglyceridemia } \\
\text { Total cholesterol levels are } \\
\text { normal or slightly reduced }\end{array}$ & $\begin{array}{l}\text { LDL } \\
\text { HDL } \\
\text { VLDL }\end{array}$ & $\begin{array}{l}\leftrightarrow \text { or } \downarrow \\
\downarrow \\
\uparrow\end{array}$ & $\begin{array}{l}1 \\
2 \\
3\end{array}$ & $\begin{array}{l}\text { Therapeutic lifestyle changes } \\
\text { Statin to reduce LDL to the goal of }<100 \mathrm{mg} / \mathrm{dl} \\
\text { Fibrates, nicotinic acid and ezetimibe in addition } \\
\text { to statin }\end{array}$ \\
\hline $\begin{array}{l}\text { Nephrotic } \\
\text { syndrome }\end{array}$ & $\begin{array}{l}\text { Hypercholesterolemia } \\
\text { Hypertriglyceridemia }\end{array}$ & $\begin{array}{l}\text { LDL } \\
\text { HDL } \\
\text { VLDL }\end{array}$ & $\begin{array}{l}\uparrow \\
\downarrow \\
\leftrightarrow \text { or } \uparrow\end{array}$ & $\begin{array}{l}1 \\
2\end{array}$ & $\begin{array}{l}\text { Statin to reduce LDL to the goal of }<100 \mathrm{mg} / \mathrm{dl} \\
\text { Fibrates, nicotinic acid and ezetimibe in addition } \\
\text { to statin }\end{array}$ \\
\hline Hemodialysis & $\begin{array}{l}\text { Hypertriglyceridemia } \\
\text { Total cholesterol levels are normal, } \\
\text { slightly reduced or slightly increased }\end{array}$ & $\begin{array}{l}\text { LDL } \\
\text { HDL } \\
\text { VLDL }\end{array}$ & $\begin{array}{l}\leftrightarrow \text { or } \downarrow \\
\downarrow \\
\uparrow\end{array}$ & $\begin{array}{l}1 \\
2 \\
3 \\
4\end{array}$ & $\begin{array}{l}\text { Statins with limited renal excretion } \\
\text { Ezetimibe in addition to statin } \\
\omega-3 \text { fatty acids in mixed dyslipidemia } \\
\text { Avoiding fibrate use in uremic patients }\end{array}$ \\
\hline $\begin{array}{l}\text { Peritoneal } \\
\text { dialysis }\end{array}$ & $\begin{array}{l}\text { Hypercholesterolemia } \\
\text { Hypertriglyceridemia }\end{array}$ & $\begin{array}{l}\text { LDL } \\
\text { HDL } \\
\text { VLDL }\end{array}$ & $\begin{array}{l}\uparrow \\
\downarrow \\
\uparrow\end{array}$ & 1 & Statin to reduce $\mathrm{LDL}$ to the goal of $<100 \mathrm{mg} / \mathrm{dl}$ \\
\hline $\begin{array}{l}\text { Kidney } \\
\text { transplantation }\end{array}$ & $\begin{array}{l}\text { Hypercholesterolemia } \\
\text { Hypertriglyceridemia }\end{array}$ & $\begin{array}{l}\text { LDL } \\
\text { HDL } \\
\text { VLDL }\end{array}$ & $\begin{array}{l}\uparrow \\
\leftrightarrow \text { or } \uparrow \\
\uparrow\end{array}$ & $\begin{array}{l}1 \\
2\end{array}$ & $\begin{array}{l}\text { Statin to reduce } \mathrm{LDL} \text { to the goal of }<100 \mathrm{mg} / \mathrm{dl} \\
\text { Ezetimibe in addition to statin }\end{array}$ \\
\hline
\end{tabular}

LDL = Low-density lipoprotein; HDL = high-density lipoprotein; VLDL = very-low-density lipoprotein; $\downarrow=$ decrease; $\uparrow=$ increase; $\leftrightarrow=$ no change.

\section{Kidney Transplantation}

The prevalence of dyslipidemias in kidney transplant recipients is very high. Particularly common are increases in total cholesterol and LDL. Triglycerides are often increased, but HDL is usually normal.

Immunosuppressive agents, e.g., prednisone, cyclosporine (Cya), and sirolimus play a major role in posttransplant dyslipoproteinemia, and they are potential remediable causes of dyslipidemias in patients with CKD and after kidney transplantation.

Glucocorticosteroids cause increases in insulin resistance and hepatic glucose output, causing hyperglycemia to worsen, and an increase in triglycerides and variable changes in HDL cholesterol levels [73].

While azathioprine does not influence glucidic and lipid metabolism, Cya has an effect on lipids, causing an increase in triglycerides and $\mathrm{Lp}(\mathrm{a})$ levels.

Artz et al. [74] have shown that the conversion of Cya to tacrolimus, azathioprine or mycophenolate mofetil is followed by a significant decrease in the levels of total and LDL cholesterol and concentrations of triglycerides.

Tacrolimus is similar to Cya concerning its toxicity, while it exerts less effects on lipid metabolism. The main collateral effects of rapamycin assumption are hypertriglyceridemia and hypercholesterolemia associated with thrombocytopenia. It is not clear how soon these agents exert their effects on lipoprotein metabolism.

\section{Therapeutic Measures}

In 2004, the National Kidney Foundation introduced guidelines on the assessment and management of dyslipidemias in kidney transplant patients, recommending that kidney transplantation be treated as a 'coronary heart disease risk equivalent' and that LDL should be lowered to $<100 \mathrm{mg} / \mathrm{dl}$ in these patients [75].

The present guidelines are consistent with those of the American Society of Transplantation, which recommend that lipid profile should be measured during the first 6 months after transplantation, 1 year after transplantation, and annually thereafter. The American Society of Transplantation guidelines also suggest that changes in immunosuppressive therapy, graft function, or CVD risk warrant additional testing [76].

However, the evidence supporting these guidelines came from only one randomized trial in the field, the Assessment of LEscol in Renal Transplantation trial (ALERT trial), and its extension study [77, 78]. ALERT is the first 
and only large-scale cardiovascular outcome trial to be conducted in transplant recipients and compared fluvastatin with placebo in 2,102 renal transplant recipients followed for 5-6 years [77].

Cosio et al. [79] reported that lipid-lowering therapy with a statin was associated with a $24 \%$ reduction in allcause mortality in 1,574 patients after renal transplantation.

Wiesbauer et al. [80] studied the association of statin use in a cohort of 2,041 first-time recipients of renal allografts between 1990 and 2003, demonstrating that statin use was independently associated with reduced allcause mortality in renal transplant recipients and with prolonged patient survival, while no difference in graft survival was detected.

Ezetimibe has also shown efficacy in the therapy of hypercholesterolemia in kidney transplant patients in several studies [81, 82]. López et al. [83] undertook a prospective study of 24 kidney transplant recipients with dyslipidemia who started treatment with $10 \mathrm{mg}$ ezetimibe; statins were being taken by $96 \%$ of these patients. None of the 24 patients who were receiving statins managed to lower their levels of total cholesterol or LDL cholesterol to the recommended levels, but the addition of ezetimibe enabled these objectives to be attained [83].

\section{Conclusions}

The pathogenesis of abnormal lipid metabolism complicating CKD is complex and the consequences of the resultant dyslipidemia are not properly understood and optimal management remains to be established (table 1).

The primary beneficial effect of statins is the reduction in LDL cholesterol levels. There is a growing literature to suggest that statins may also have beneficial cholesterol-independent effects on endothelial function, inflammation, and perhaps other aspects of vascular function.
Potential indications for statins in patients with renal disease might be to assist in the reduction of proteinuria or to reduce the rate of loss of glomerular filtration (progression) apart from the goal of reducing cardiovascular events.

Currently there is no evidence to support treating HD patients, indeed the lack of cardiovascular benefit with statins in both the AURORA and the $4 \mathrm{D}$ suggests that CVD in HD patients is different compared with that in the non-renal population.

There is a need for further research and analysis of data and to explore new approaches and treatment strategies for reducing the high risk of CVD in HD patients.

However, in the future, the results of the ongoing trials, like the SHARP trial, will hopefully put an end to current uncertainties and place recommendations on statin use on more solid footing, for renal patients with CKD in general and HD patients more specifically.

Because statins are relatively safe and the evidence for lowering cholesterol to reduce CVDs is so overwhelmingly positive in non-HD patients, it is reasonable to continue treating these patients until future trials are completed.

Whatever the cause, we believe that the decision for the administration of statins in HD patients should be individualized.

A number of other hypolipidemic drugs that are increasingly being used in the general population (such as niacin, $\omega-3$ polyunsaturated fatty acids and ezetimibe) may also play important roles in the management of uremic dyslipidemia.

Recent evidence suggests that statin therapy may also have a renoprotective effect. However, large studies are needed and, in part are already ongoing, to confirm these additional beneficial effects.

As concerns transplant patients, there is a need for individually adjusted immunosuppressive therapy which possibly necessitates the use of hypolipidemic drugs in dyslipidemic kidney graft recipients.
References

Kidney Blood Press Res 2010;33:100-110
Attman PO, Alaupovic P: Lipid and apolipoprotein profiles of uremic dyslipoproteinemia: relation to renal function and dialysis. Nephron 1991;57:401-410.

-2 Kronenberg F, Kuen E, Ritz E, et al: Apolipoprotein A-IV serum concentrations are elevated in mild and moderate renal failure. J Am Soc Nephrol 2002;13:461-469.
Keith DS, Nichols GA, Gullion CM, et al: Longitudinal follow-up and outcomes among a population with chronic kidney disease in a large managed care organization. Arch Intern Med 2004;164:659-663.

4 Vaziri ND, Moradi H: Mechanisms of dyslipidemia of chronic renal failure. Hemodial Int 2006;10:1-7. 
$\checkmark 5$ Vaziri ND: Dyslipidemia of chronic renal failure: the nature, mechanisms, and potential consequences. Am J Physiol Renal Physiol 2006;290:F262-F272.

$\checkmark 6$ Prinsen BH, de Sain-van der Velden MG, de Koning EJ et al: Hypertriglyceridemia in patients with chronic renal failure: possible mechanisms. Kidney Int Suppl 2003; 84:S121-S124.

7 Mori Y, Hirano T, Nagashima M, et al: Decreased peroxisome proliferator-activated receptor alpha gene expression is associated with dyslipidemia in a rat model of chronic renal failure. Metabolism 2007;56:17141718.

$\checkmark 8$ Vaziri ND, Deng G, Liang K: Hepatic HDL receptor, SR-B1 and Apo A-I expression in chronic renal failure. Nephrol Dial Transplant 1999;14:1462-1466.

-9 Guarnieri GF, Moracchiello M, Campanacci L, et al: Lecithin-cholesterol acyltransferase (LCAT) activity in chronic uremia. Kidney Int Suppl 1978;8:S26-S30.

10 Kimura H, Miyazaki R, Imura T, et al: Hepatic lipase mutation may reduce vascular disease prevalence in hemodialysis patients with high CETP levels. Kidney Int 2003;64: 1829-1837.

-11 St Pierre AC, Cantin B, Dagenais GR et al: Low-density lipoprotein subfractions and the long-term risk of ischemic heart disease in men: 13-year follow-up data from the Quebec Cardiovascular Study. Arterioscler Thromb Vasc Biol 2005;25:553-559.

12 Danesh J, Collins R, Peto R: Lipoprotein(a) and coronary heart disease: meta-analysis of prospective studies. Circulation 2000;102: 1082-1085.

13 Kronenberg F, Kuen E, Ritz E, et al: Lipoprotein(a) serum concentrations and apolipoprotein(a) phenotypes in mild and moderate renal failure. J Am Soc Nephrol 2000;11:105-115.

14 National Kidney Foundation: K/DOQI Clinical Practice Guidelines for Managing Dyslipidemias in Chronic Kidney Disease. Guideline 4. New York, National Kidney Foundation, 2002.

-15 Expert Panel on Detection Evaluation and Treatment of High Blood Cholesterol in Adults: Executive Summary of the Third Report of the National Cholesterol Education Program (NCEP) Expert Panel on Detection, Evaluation, and Treatment of High Blood Cholesterol in Adults (Adult Treatment Panel III). JAMA 2001;285:2486-2497.

16 Rubins HB, Robins SJ, Collins D, et al: Diabetes, plasma insulin, and cardiovascular disease: subgroup analysis from the Department of Veterans Affairs High-Density Lipoprotein Intervention Trial (VA-HIT). Arch Intern Med 2002;162:2597-2604.

-17 Deighan CJ, Caslake MJ, McConnell M, et al: The atherogenic lipoprotein phenotype: small dense LDL and lipoprotein remnants in nephrotic range proteinuria. Atherosclerosis $2001 ; 157: 211-220$.
18 Vaziri ND, Sato T, Liang K: Molecular mechanism of altered cholesterol metabolism in focal glomerulosclerosis. Kidney Int 2003; 63:1756-1763.

19 Vaziri ND: Molecular mechanisms of lipid disorders in nephrotic syndrome. Kidney Int 2003;63:1964-1976.

20 Vaziri ND, Liang K, Park JS: Acquired lecithin: cholesterol acyltransferase (LCAT) deficiency in nephrotic syndrome. Am J Physiol 2001;49:F823-F829.

21 Vaziri ND, Kim CH, Phan D, et al: Up-regulation of hepatic Acyl CoA: diacylglycerol acyltransferase-1 (DGAT-1) expression in nephrotic syndrome. Kidney Int 2004;66: 262-267.

22 Tsimihodimos V, Dounousi E, Siamopoulos KC: Dyslipidemia in chronic kidney disease: an approach to pathogenesis and treatment. Am J Nephrol 2008;28:958-973.

23 Ordonez JD, Hiatt RA, Killebrew EJ, Fireman BH: The increased risk of coronary heart disease associated with nephrotic syndrome. Kidney Int 1993;44:638-642.

24 Lechner BL, Bockenhauer D, Iragorri S, et al: The risk of cardiovascular disease in adults who have had childhood nephrotic syndrome. Pediatr Nephrol 2004;19:744-748.

25 Fried LF, Orchard TJ, Kasiske BL; for the Lipids and Renal Disease Progression Metaanalysis Study Group: Effect of lipid reduction on the progression of renal disease: a meta-analysis. Kidney Int 2001;59:260-269.

26 Gheit OA, Sobh MA, Mohamed Kel-S, et al: Impact of treatment of dyslipidemia on renal function, fat deposits and scarring in patients with persistent nephrotic syndrome. Nephron 2002;91:612-619.

27 Valdivesio P, Moliz M, Valera A, et al: Atorvastatin in dislipidemia of the nephrotic syndrome. Nephrology 2003;8:61-64.

-28 Rayner BL, Byrne MJ, van Zyl Smit R: A prospective clinical trial comparing the treatment of idiopathic membranous nephropathy and nephrotic syndromewith simvastatin and diet, versus diet alone. Clin Nephrol 1996;46:219-224.

29 Dalrymple LS, Kaysen GA: The effect of lipoproteins on the development and progression of renal disease. Am J Nephrol 2008;28: 723-731.

30 Brunskill NJ: Albumin signals the coming of age of proteinuric nephropathy. J Am Soc Nephrol 2004;15:504-505.

31 Vaziri ND: Dyslipidemia of chronic renal failure: the nature, mechanisms, and potential consequences. Am J Physiol Renal Physiol 2006;290:F262-F272.

>32 Muntner P, Coresh J, Smith JC, et al: Plasma lipids and risk of developing renal dysfunction: the Atherosclerosis Risk in Communities Study. Kidney Int 2000;58:293-301.
33 Samuelsson O, Attman PO, Knight-Gibson $\mathrm{C}$ et al: Complex apolipoprotein B-containing lipoprotein particles are associated with a higher rate of progression of human chronic renal insufficiency. J Am Soc Nephrol 1998;9:1482-1488.

-34 Ozsoy RC, van der Steeg WA, Kastelein JJ, et al: Dyslipidaemia as predictor of progressive renal failure and the impact of treatment with atorvastatin. Nephrol Dial Transplant 2007;22:1578-1586.

-35 Schaeffner ES, Kurth T, Curhan GC, et al: Cholesterol and the risk of renal dysfunction in apparently healthy men. J Am Soc Nephrol 2003; 14:2084-2091.

36 Scheuer H, Gwinner W, Hohbach J, et al: Oxidant stress in hyperlipidemia-induced renal damage. Am J Physiol Renal Physiol 2000; 78:F63-F74.

37 Buemi M, Senatore M, Corica F, et al: Are there potential non-lipid-lowering uses of statins in the kidney? Nephron 2001;89:363368.

-38 Buemi M, Senatore M, Corica F, et al: Statins and progressive renal disease. Med Res Rev 2002;22:76-84.

$>39$ Buemi M, Corica F, Marino D, et al: Cardiovascular remodelling, apoptosis and drugs. Am J Hyperten 2000;13:450-454.

$\checkmark 40$ Buemi M, Allegra A, Senatore M, et al: Proapoptotic effect of fluvastatin on human smooth muscle cells. Eur J Pharmacol 1999; 370:201-203.

41 Buemi M, Nostro L, Crascì E, et al: Statins in nephrotic syndrome: a new weapon against tissue injury. Med Res Rev 2005; 25:587-609.

42 Zhou MS, Jaimes EA, Raij L: Atorvastatin prevents end-organ injury in salt-sensitive hypertension: role of eNOS and oxidant stress. Hypertension 2004;44:186-190.

43 Tonelli M, Isles C, Curhan GC, et al: Effect of pravastatin on cardiovascular events in people with chronic kidney disease. Circulation 2004;110:1557-1563.

44 Agarwal R: Effects of statins on renal function. Am J Cardiol 2006;97:748-755.

45 Abbate M, Zoja C, Corna D, et al: In progressive nephropathies, overload of tubular cells with filtered proteins translates glomerular permeability dysfunction into cellular signals of interstitial inflammation. J Am Soc Nephrol 1998;9:1213-1224.

46 Sandhu S, Wiebe N, Fried LF, Tonelli M: Statins for improving renal outcomes: a meta-analysis. J Am Soc Nephrol 2006;17:20062016.

47 Kilpatrick RD, McAllister CJ, Kalantar-Zadeh K: Comparing mortality-predictability of serum total cholesterol and low density lipoprotein (LDL) cholesterol in hemodialysis patients. J Am Soc Nephrol 2005;16:728A.

48 Liu Y, Coresh J, Eustace JA, et al: Association between cholesterol level and mortality in dialysis patients: role of inflammation and malnutrition. JAMA 2004;291:451-459. 
49 Iseki K, Yamazato M, Tozawa M, Takishita S: Hypocholesterolemia is a significant predictor of death in a cohort of chronic hemodialysis patients. Kidney Int 2002;61:18871893.

-50 Kwan BC, Kronenberg F, Beddhu S, Cheung AK: Lipoprotein metabolism and lipid management in chronic kidney disease. J Am Soc Nephrol 2007; 18:1246-1261.

51 National Kidney Foundation: K/DOQI clinical practice guidelines for managing dyslipidemias in chronic kidney disease. Am J Kidney Dis 2003;41(suppl 3):S1-S92.

-52 Attman PO, Samuelsson OG, Moberly J, et al: Apolipoprotein B-containing lipoproteins in renal failure: the relation to mode of dialysis. Kidney Int 1999;55:1536-1542.

53 Okubo K, Ikewaki K, Sakai S, et al: Abnormal HDL apolipoprotein A-I and A-II kinetics in hemodialysis patients: a stable isotope study. J Am Soc Nephrol 2004;15:1008-1015.

54 Blankestijn PJ, Vos PF, Rabelink TJ, et al: High-flux dialysis membranes improve lipid profile in chronic hemodialysis patients. J Am Soc Nephrol 1995;5:1703-1708.

-55 Näsström B, Stegmayr B, Gupta J et al: A single bolus of a low molecular weight heparin to patients on haemodialysis depletes lipoprotein lipase stores and retards triglyceride clearing. Nephrol Dial Transplant 2005;20: 1172-1179.

56 Kidney Disease Outcomes Quality Initiative (K/DOQI) Group: K/DOQI clinical practice guidelines for management of dyslipidemias in patients with kidney disease. Am J Kidney Dis 2003;41(suppl 3):I-IV, S1-S91.

57 Navaneethan SD, Shrivastava R: HMG CoA reductase inhibitors (statins) for dialysis patients. Cochrane Database Syst Rev 2004; 4:CD004289.

-58 Launay-Vacher V, Izzedine H, Deray G: Statins' dosage in patients with renal failure and cyclosporine drug-drug interactions in transplant recipient patients. Int J Cardiol 2005;101:9-17.

59 Tonelli M, Isles C, Craven T, et al: Effect of pravastatin on rate of kidney function loss in people with or at risk for coronary disease. Circulation 2005;112:171-178.
60 Kosoglou T, Statkevich P, Johnson-Levonas $\mathrm{AO}$, et al: Ezetimibe: a review of its metabolism, pharmacokinetics and drug interactions. Clin Pharmacokinet 2005;44:467494.

61 Davidson MH, Armani A, McKenney JM, Jacobson TA: Safety considerations with fibrate therapy. Am J Cardiol 2007;99:3C$18 \mathrm{C}$.

62 Wanner C, Krane V, März W, et al; for the German Diabetes and Dialysis Study Investigators: Atorvastatin in patients with type 2 diabetes mellitus undergoing hemodialysis. N Engl J Med 2005;353:238-248.

63 Fathi R, Isbel N, Short L, et al: The effect of long-term aggressive lipid lowering on ischemic and atherosclerotic burden in patients with chronic kidney disease. Am J Kidney Dis 2004;43:45-52.

64 Schwarz U, Buzello M, Ritz E, Stein G, et al: Morphology of coronary atherosclerotic lesions in patients with end-stage renal failure. Nephrol Dial Transplant 2000;15:218-223.

65 Fellström BC, Jardine AG, Schmieder RE Rosuvastatin and cardiovascular events in patients undergoing hemodialysis. N Engl Med 2009;360:1395-1407.

66 Baigent C, Landry M: Study of Heart and Re nal Protection (SHARP). Kidney Int 2003; 63(suppl):S207-S210.

67 Molitch ME: Management of dyslipidemias in patients with diabetes and chronic kidney disease. Clin J Am Soc Nephrol 2006;1:10901099.

68 Prinsen BH, Rabelink TJ, Romijn JA, et al: A broad-based metabolic approach to study VLDL apoB100 metabolism in patients with ESRD and patients treated with peritoneal dialysis. Kidney Int 2004;65:1064-1075.

69 Babazono T, Nakamoto H, Kasai K, et al: Effects of icodextrin on glycemic and lipid profiles in diabetic patients undergoing peritoneal dialysis. Am J Nephrol 2007;27:409-415.

70 Paraskevas KI: Statin therapy in peritoneal dialysis patients: effects beyond lipid lowering. Int Urol Nephrol 2008;40:165-170.

71 Calabrò P, Yeh ET: The pleiotropic effects of statins. Curr Opin Cardiol 2005;20:541-546.

72 Haslinger B, Goedde MF, Toet KH, et al: Simvastatin increases fibrinolytic activity in human peritoneal mesothelial cells independent of cholesterol lowering. Kidney Int 2002;62:1611-1619.
73 Trence DL: Management of patients on chronic glucocorticoidi therapy: an endocrine perspective. Prim Care 2003;30:593605.

74 Artz MA, Boots JM, Ligtenberg G, et al: Improved cardiovascular risk profile and renal function in renal transplant patients after randomized conversion from cyclosporine to tacrolimus. J Am Soc Nephrol 2003; 14: 1880-1888.

75 Kasiske B, Cosio FG, Beto J, et al: Clinical practice guidelines for managing dyslipidemias in kidney transplant patients: a report from the Managing Dyslipidemias in Chronic Kidney Disease Work Group of the National Kidney Foundation Kidney Disease Outcomes Quality Initiative. Am J Transplant 2004;4(suppl 7):13.

-76 Kasiske BL, Vazquez MA, Harmon WE, et al: Recommendations for the outpatient surveillance of renal transplant recipients. J Am Soc Nephrol 2000;11:S1.

$>77$ Holdaas H, Fellström B, Jardine A, et al: Effect of fluvastatin on cardiac outcomes in renal transplant recipients: a multicentre, randomised, placebo-controlled trial. Lancet 2003;361:2024-2031.

78 Holdaas H, Fellström B, Cole E, et al: Longterm cardiac outcomes in renal transplant recipients receiving fluvastatin: the ALERT extension study. Am J Transplant 2005;5: 2929-2936.

$>79$ Cosio FG, Pesavento TE, Pelletier RP, et al: Patient survival after renal transplantation: the effects of statins. Am J Kidney Dis 2002; 40:638-643.

$>80$ Wiesbauer F, Heinze G, Mitterbauer C, et al: Statin use is associated with prolonged survival of renal transplant recipients. J Am Soc Nephrol 2008;19:2211-2218.

81 Puthenparumpil J, Keough-Ryan T, Kibed $\mathrm{M}$, et al: Treatment of hypercholesterolemia with ezetimibe in the kidney transplant population. Transplant Proc 2005;37:1033.

$>82$ Buchanan C, Smith L, Corbett J, et al: A retrospective analysis of ezetimibe treatment in renal transplant recipients. Am J Transplant 2006;6:770-774.

83 López V, Gutiérrez C, Gutiérrez E, et al: Treatment with ezetimibe in kidney transplant recipients with uncontrolled dyslipidemia. Transplant Proc 2008;40:2925-2926. 